\title{
Effect of YHHJ on the expression of the hepatocellular bile acid transporters multidrug resistance-associated protein 2 and bile salt export pump in ethinylestradiol-induced cholestasis
}

\author{
JIA LIU, LI-LI HOU and CUI-YING ZHAO \\ Department of Traditional Chinese Medicine, The Affiliated Obstetrics and Gynecology Hospital \\ of Nanjing Medical University, Nanjing Maternity and Child Health Care Hospital, Nanjing, Jiangsu 210004, P.R. China
}

Received October 20, 2016; Accepted September 1, 2017

DOI: $10.3892 /$ etm.2018.5891

\begin{abstract}
The herbal medicine Yin Huang Mixture (YHHJ; patent no. 200910031240.7) is an aqueous extract composed from various herbs, including Artemisia capillaries Thunb, Hypericum japonicum Thunb, Eucommia ulmoides Oliver, Rheum officinale Baill, Gardenia jasminoides Ellis, Poria cocos Wolf and Dictamnus dasycarpus Turcz. Previous studies have indicated that YHHJ treatment has a beneficial effect on ameliorating itching and reducing serum bile acid levels in patients with intrahepatic cholestasis of pregnancy (ICP). However, the molecular mechanisms of action of YHHJ in ICP have not been fully elucidated. Therefore, the present study investigated an experimental hepatocellular cholestasis model to explore the regulatory role of $\mathrm{YHHJ}$ on the expression of the bile acid carriers, multidrug resistance-associated protein 2 (MRP2) and the bile salt export pump (BSEP). Initially, $5 \mathrm{mg} / \mathrm{kg} /$ day 17 - $\alpha$ ethinylestradiol (EE) was used to induce cholestasis in rats and primary isolated rat hepatocytes. Subsequently, 9 or $36 \mathrm{~g} / \mathrm{kg} /$ day YHHJ water extract was administrated. Blood samples were collected and serum biochemical parameters of total bile acids (TBA), total bilirubin (TBil), alanine transaminase and aspartate aminotransferase levels were determined. Rat livers and primary isolated rat hepatocytes were obtained and the protein and mRNA expression levels of MRP2 and BSEP were analyzed by western blot analysis and reverse transcription-quantitative polymerase chain reaction, respectively. Results revealed that EE-induced hepatocellular cholestasis was associated with a
\end{abstract}

Correspondence to: Mrs. Li-Li Hou, Department of Traditional Chinese Medicine, The Affiliated Obstetrics and Gynecology Hospital of Nanjing Medical University, Nanjing Maternity and Child Health Care Hospital, 123 Tianfei Lane, Nanjing, Jiangsu 210004, P.R. China

E-mail: hlldoctor123@126.com

Key words: YHHJ, 17- $\alpha$ ethinylestradiol, intrahepatic cholestasis of pregnancy, multidrug resistance-associated protein 2 , bile salt export pump significant increase in serum TBA and TBil levels, whereas, YHHJ treatment significantly reversed this effect $(\mathrm{P}<0.01)$. Further experiments on the molecular mechanism revealed that EE significantly decreased the expression of MRP2 and BSEP compared with the control group, whereas YHHJ treatment significantly upregulated MRP2 and BSEP expression in vivo and in vitro compared with no YHHJ treatment $(\mathrm{P}<0.01)$. In addition, to establish whether upregulation of MRP2 and BSEP protein expression levels resulted from increased expression of their respective mRNA, the mRNA expression levels were determined. Results indicated that YHHJ treatment significantly increased MRP2 and BSEP mRNA expression levels in EE-induced hepatocellular cholestasis compared with no YHHJ treatment $(\mathrm{P}<0.01)$. In conclusion, the present findings suggest that YHHJ effects EE-induced cholestasis and this process may be mediated through regulating hepatobiliary transporters, MRP2 and BSEP.

\section{Introduction}

Intrahepatic cholestasis of pregnancy (ICP) is a liver disorder, which occurs predominantly during the third trimester of pregnancy (1). ICP is characterized by pruritus, jaundice, high serum bile acid levels and abnormal liver function, which adversely affects fetal health (1). Although the etiology of ICP is not fully understood, previous results have suggested that female hormones may have a causative role (2).

Previous findings have indicated an etiologic role for estrogens in the initiation of ICP (3). ICP typically occurs in the last trimester, when estrogen levels are highest (4). In addition, ICP is more common in multiple pregnancies compared with single pregnancies (5). The estrogen oral contraceptive used among women with a personal or family history of ICP may result in clinical features of ICP, including pruritus, elevated serum aminotransferases and bile acid levels, particularly when former high-dose preparations were used (6).

The synthetic estrogen $17 \alpha$-ethinylestradiol (EE) has been demonstrated to reduce bile flow formation in experimental animals (7). In vitro studies have reported that EE impairs the expression and function of hepatocyte transporters, including multidrug resistance-associated protein 2 (MRP2) and the bile salt export pump (BSEP), 
which have important roles in bile salt-dependent component of bile flow (BSDF) and bile salt-independent flow (BSIF) (8-10). Furthermore, ICP induced by EE in rodents is an established animal model to assess the mechanisms of estrogen-induced cholestasis (11).

Herb decoction of Chinese medicine is an effective method and has been used in the clinic to treat ICP $(12,13)$. Yin Huang Mixture (YHHJ; patent no. 200910031240.7) is a clinical experiential decoction that was formulated in the Maternal and Child Health Medical Institute (Obstetrics and Gynecology Hospital, Nanjing, China) and was predominantly composed of Artemisia capillaries Thunb, Hypericum japonicum Thunb, Eucommia ulmoides Oliver, Rheum officinale Baill, Gardenia jasminoides Ellis, Poria cocos Wolf and Dictamnus dasycarpus Turcz. YHHJ has been used to treat ICP in clinic for decades. YHHJ has previously been revealed to ameliorate itching and reduce serum bile acid levels, is well tolerated by pregnant women and has no adverse effects in mothers or newborns $(14,15)$. However, the molecular mechanism of YHHJ on ICP remains to be elucidated.

The present study focused on the action of YHHJ in regulating membrane transporters, particularly MRP2, which transports lipophilic substances and contributes to the formation of BSDF (16) and the BSEP, which mediates the concentrative transport of monovalent bile salts into the canaliculus and generates the BSIF (17), using rats and primary isolated rat hepatocytes with EE-induced cholestasis.

\section{Materials and methods}

Preparation of YHHJ. The aforementioned herbs (Department of Pharmacy, Obstetrics and Gynecology Hospital Affiliated to Nanjing Medical University, Nanjing, China) were soaked in water for $0.5 \mathrm{~h}$ at room temperature, followed by two cycles of reflux extraction. The first round of reflux extraction used $10 \mathrm{l}$ of water and was performed for $2 \mathrm{~h}$ at $80-100^{\circ} \mathrm{C}$, whereas the second round used 81 of water and was performed for $1 \mathrm{~h}$ at $80-100^{\circ} \mathrm{C}$. The decoction was subsequently filtered through double gauze and the filtrate was concentrated under reduced pressure $\left(0.1-0.5 \mathrm{kgf} / \mathrm{cm}^{2}\right)$ using a rotary evaporator to a final concentration that was equivalent to $1.8 \mathrm{~g}$ crude $\mathrm{drug} / \mathrm{ml}$ of solution. The residue was stored at $4^{\circ} \mathrm{C}$ until use.

Animals and treatment. In the present study, 50 male Sprague-Dawley rats (age, 6-8 weeks) were purchased from Shanghai Laboratory Animal Centre (SLAC) Laboratory Animal Co., Ltd. (Shanghai, China) with an initial body weight of 180-200 g. Rats had ad libitum access to a standard laboratory diet and water and were housed at room temperature with a humidity of 50\% and a $12 \mathrm{~h}$ light/dark cycle. Rats were divided into the model group $(n=30)$ and a control group $(n=10)$. In the model group, rats received $5 \mathrm{mg} / \mathrm{kg} /$ day EE (Sigma-Aldrich; Merck KGaA, Darmstadt, Germany) via intraperitoneal injection for 10 consecutive days to induce cholestasis, which was confirmed by measuring serum alanine transaminase (ALT), aspartate aminotransferase (AST), serum total bile acid (TBA) and total bilirubin (TBil). In the control group (N), rats received similar volumes of propylene glycol $(2.5 \mathrm{ml} / \mathrm{kg} / \mathrm{day}$; Panreac Quimica SLU, Barcelona, Spain; solvent vehicle). On day 11 following EE initiation, the model group was further divided into three groups ( $\mathrm{n}=10$ each): Model (M), low-dose YHHJ (YL) and high-dose YHHJ (YH) groups. The YL and YH groups were gavaged with YHHJ (9 and $36 \mathrm{~g} / \mathrm{kg} / \mathrm{day}$, respectively) continuously for a total of 14 days. In parallel experiments, the $\mathrm{N}$ and $\mathrm{M}$ groups were gavaged with distilled water.

Sample collection. On the 10th day following EE administration, rats from each group were anesthetized with pentobarbital sodium, $(50 \mathrm{mg} / \mathrm{kg}$ viaintraperitoneal injection; Panreac Quimica SLU) and plasma samples were extracted from the retro-orbital plexus. Rats were sacrificed and the liver was weighed prior to being aliquoted for mRNA and protein extraction.

Biochemical analyses. TBA levels were determined from plasma samples using a radioimmunoassay kit (cat. no. 50004463; Diasys Diagnostic Systems GmbH, Holzheim, Germany). Serum concentrations of TBil (cat. no. CH0101003; Maccura Biotechnology Co., Ltd., Chengdu, China), ALT (cat. no. 1.02.1203; Shanghai Fuxing Changzheng Medical Science Co., Ltd., Shanghai, China) and AST (cat. no. 1.02.1003; Shanghai Fuxing Changzheng Medical Science Co., Ltd.) were determined using kits and measured using an automated biochemical analyzer (Beckman Coulter, Inc., Brea, CA, USA). All kits were performed according to the manufacturer's instructions.

Hepatocyte isolation. Hepatocytes were harvested from the normal livers of an additional 10 male Sprague-Dawley rats according to the Seglen method with certain modifications, including the insertion of the liver perfusion catheter through the right atrium and suprahepatic vena cava (18). Cell viability was determined using the trypan blue exclusion test (18). Freshly isolated hepatocytes were seeded onto collagen-coated 6-well plates at a density of $2 \times 10^{5}$ cells $/ \mathrm{ml}$ in Williams medium E (Invitrogen; Thermo Fisher Scientific, Inc., Waltham, MA, USA) supplemented with penicillin $(100 \mathrm{IU} / \mathrm{ml})$, streptomycin $(100 \mu \mathrm{g} / \mathrm{ml})$, insulin $(4 \mu \mathrm{g} / \mathrm{ml})$, dexamethasone $(10 \mathrm{nmol} / \mathrm{l})$ and $10 \%(\mathrm{v} / \mathrm{v})$ fetal bovine serum (Invitrogen). Cells were incubated at $37^{\circ} \mathrm{C}$ in a humidified atmosphere containing $5 \% \mathrm{CO}_{2}$.

Cytotoxic assay. The cytotoxic effect of YHHJ on hepatocyte cells was evaluated using the XTT assay. Cells were seeded onto 96 -well culture plates at $1 \times 10^{4}$ cells/well. Following a $4 \mathrm{~h}$ incubation at $37^{\circ} \mathrm{C}$, various concentrations of YHHJ $(0,100,200,300,400,500,600,700,800,900$ and $1,000 \mu \mathrm{g} / \mathrm{ml}$ ) were added into each well. The plate was subsequently incubated at $37^{\circ} \mathrm{C}$ in an atmosphere containing $5 \% \mathrm{CO}_{2}$ for $72 \mathrm{~h}$. The medium (YHHJ water extract) was discarded and $50 \mu \mathrm{l}(1 \mathrm{mg} / \mathrm{ml})$ XTT reagent (Sigma-Aldrich; Merck $\mathrm{KGaA}$ ) was added and the plates were re-incubated at $37^{\circ} \mathrm{C}$ for an additional $3 \mathrm{~h}$ to allow the development of formazan. The optical densities were subsequently measured with an ELISA reader (PerkinElmer, Inc., Waltham, MA, USA) at a wavelength of $450 \mathrm{~nm}$. The $50 \%$ cytotoxic concentration $\left(\mathrm{CC}_{50}\right)$ was defined as the concentration of YHHJ extract that reduced the cell viability by $50 \%$ when compared with untreated controls. 
Table I. Primers for quantitative reverse transcription-quantitative polymerase chain reaction.

\begin{tabular}{lll}
\hline Gene & \multicolumn{1}{c}{ Forward sequence } & \multicolumn{1}{c}{ Reverse sequence } \\
\hline Rat MRP2 & 5'-CCAATGTTTTGAATGCGGAG-3' & 5'-GTACCACTGGAGTAGCTAGGA-3' \\
Rat BSEP & 5'-CACTGGCCTTCTGGTATGGT-3' & 5'-CAGTCCTCTGCCGATGTTCG-3' \\
Rat GAPDH & 5'-AATGTATCCGTTGTGGATCTGA-3' & 5'-TCTTCCACCACTTCGTCCG-3'
\end{tabular}

MRP2, multidrug resistance-associated protein 2; BSEP, bile salt export pump.

Hepatocyte culture and treatment. Following a $12 \mathrm{~h}$ incubation at $37^{\circ} \mathrm{C}$, the Williams medium $\mathrm{E}$ was refreshed. When hepatocytes reached a density of $2 \times 10^{5}$ cells/well, they were incubated in the presence or absence of $1 \mu \mathrm{mol} / 1 \mathrm{EE}$ for $12 \mathrm{~h}$ at $37^{\circ} \mathrm{C}$. Subsequently, the medium was aspirated and the hepatocytes were treated with (YH group) or without (KB group) YHHJ (300 $\mu \mathrm{g} / \mathrm{ml}$ as determined by XTT assay) in Williams medium E containing $0.2 \%$ bovine serum albumin (Invitrogen) for $24 \mathrm{~h}$ at $37^{\circ} \mathrm{C}$.

Extraction of membrane fraction. Ground liver tissues were centrifuged at a speed of $1,100 \mathrm{x} \mathrm{g}$ for $15 \mathrm{~min}$ at $4^{\circ} \mathrm{C}$. Hepatocyte pellets were then collected and homogenized in radioimmunoprecipitation assay extraction buffer containing protease inhibitors $(25 \mu \mathrm{g} / \mathrm{ml}$ leupeptin and $1 \mathrm{mmol} / \mathrm{l}$ phenylmethylsulfonyl fluoride; Beyotime Institute of Biotechnology, Haimen, China) and centrifuged at 1,100 x g for $15 \mathrm{~min}$ at $4^{\circ} \mathrm{C}$. The supernatant containing the membrane fraction was collected and stored at $-70^{\circ} \mathrm{C}$ prior to analyses. Protein concentrations of the membrane fractions were determined using the BCA protein assay kit (Pierce; Thermo Fisher Scientific, Inc., Waltham, MA, USA) according to the manufacturer's insructions (19).

Western blot analysis. An aliquot of the membrane fraction (30 $\mu \mathrm{g}$ protein) was mixed with an equal volume of sample buffer. Following heat-treating at $95^{\circ} \mathrm{C}$ for $10 \mathrm{~min}, 20 \mu \mathrm{g}$ protein samples were loaded per lane and separated using $10 \%$ SDS-PAGE and transferred to polyvinylidene fluoride (PVDF) membranes. Following incubation, membranes were blocked with $5 \%$ non-fat dried milk at room temperature for $2 \mathrm{~h}$. The PVDF membranes were then washed three times using Tris-buffered saline with $0.1 \%$ Tween-20 for $10 \mathrm{~min}$ and incubated overnight at $4^{\circ} \mathrm{C}$ with anti-MRP2 monoclonal antibody (1:500; cat. no. F0410; Abcam, Cambridge, UK) and anti-BSEP polyclonal antibody (1:1,000; cat. no. 927043; Santa Cruz Biotechnology, Inc., Dallas, TX, USA). Bound antibodies were incubated at room temperature for $2 \mathrm{~h}$ with horseradish peroxidase-conjugated anti-rabbit antibodies (1:5,000; cat. no. GR44808-4; Cell Signaling Technology, Inc., Danvers, MA, USA) and detected using an electrochemiluminescence kit (Pierce; Thermo Fisher Scientific, Inc.) according to the manufacturer's instructions and exposed to X-ray film for $1 \mathrm{~min}$. $\beta$-actin was the loading control (1:1,000; cat. no. H2906; Cell Signaling Technology, Inc.). The intensity of selected bands were captured and analysed using ImageJ software (version 1.46; National Institutes of Health, Bethesda, MD, USA).
RNA extraction and reverse transcription-quantitative polymerase chain reaction ( $R T-q P C R)$. Total RNA from rat livers and cultured hepatocytes was extracted using TRIzol reagent (Invitrogen). In each experiment, $1 \mu \mathrm{g}$ total RNA was reverse-transcribed using PrimeScript RT Reagent kit with gDNA Eraser (Takara Bio, Inc., Otsu, Japan) according to the manufacturer's instructions. PCR reactions, which contained SYBR PCR supermix (Invitrogen), cDNA and primers (Table I), were run on a LightCycler 1.5. The thermal cycling conditions consisted of $95^{\circ} \mathrm{C}$ for $15 \mathrm{sec}$, followed by 45 cycles at $95^{\circ} \mathrm{C}$ for $15 \mathrm{sec}, 58^{\circ} \mathrm{C}$ for $10 \mathrm{sec}$ and $72^{\circ} \mathrm{C}$ for $15 \mathrm{sec}$. Quantification of gene expression relative to GAPDH (the housekeeping gene) was performed using the $2^{-\Delta \Delta \mathrm{Cq}}$ method (20). All experiments were performed in triplicate.

Statisticalanalyses. Data were expressed as the mean \pm standard deviation Statistical analysis was performed using SPSS 11.0 software (SPSS, Inc., Chicago, IL, USA) one-way analysis of variance followed by Student-Newman-Keuls multiple range test. $\mathrm{P}<0.01$ was considered to indicate a statistically significant difference.

\section{Results}

Effect of YHHJ on serum cholestatic indices in EE-induced cholestatic rats. The administration of $\mathrm{EE}$ for 10 days resulted in a significant increase in serum TBA and TBil levels compared with the $\mathrm{N}$ group $(\mathrm{P}<0.01$; Table II). The protective effect of $\mathrm{YHHJ}$ on cholestasis was observed in $\mathrm{YL}$ and YH groups and the results revealed a significant reduction in serum TBA and TBil levels compared with the $M$ group $(\mathrm{P}<0.01$; Table II). Furthermore, compared with the $\mathrm{N}$ group, the $M$ group exhibited increased serum ALT and AST levels; however, the difference was not statistically significant and YHHJ did not significantly decrease serum ALT and AST levels in EE-induced cholestatic rats (Table II).

Effect of YHHJ on the protein expression levels of MRP2 and BSEP in EE-induced cholestatic rats. Consistent with previous findings (8-10), the present western blot analysis also revealed that MRP2 and BSEP protein expression levels were significantly reduced following EE treatment compared with the $\mathrm{N}$ group $(\mathrm{P}<0.01$; Fig. 1). However, these protein expression levels were significantly increased following YHHJ administration $(\mathrm{P}<0.01$; Fig. 1$)$. Results indicated that here were no significant differences in MRP2 and BSEP protein expression levels between YL and YH groups. 
Table II. Effect of YHHJ on serum cholestatic indices in EE induced cholestatic rats.

\begin{tabular}{lcccc}
\hline Group & TBA $(\mu \mathrm{mol} / \mathrm{l})$ & Tbil $(\mu \mathrm{mol} / \mathrm{l})$ & ALT (U/l) & AST $(\mathrm{U} / \mathrm{l})$ \\
\hline $\mathrm{N}$ & $1.85 \pm 0.58$ & $1.72 \pm 0.33$ & $132.61 \pm 6.42$ & $150.73 \pm 6.08$ \\
$\mathrm{M}$ & $3.55 \pm 0.89^{\mathrm{a}}$ & $3.65 \pm 0.42^{\mathrm{a}}$ & $133.63 \pm 3.41$ & $155.70 \pm 4.81$ \\
YL & $2.12 \pm 0.72^{\mathrm{b}}$ & $1.92 \pm 0.23^{\mathrm{b}}$ & $126.12 \pm 5.49$ & $156.41 \pm 5.18$ \\
YH & $2.18 \pm 0.76^{\mathrm{b}}$ & $1.95 \pm 0.3^{\mathrm{b}}$ & $126.81 \pm 3.57$ & $156.00 \pm 5.69$ \\
\hline
\end{tabular}

Values are expressed as the mean \pm standard deviation $(\mathrm{n}=10) .{ }^{\mathrm{a}} \mathrm{P}<0.01 \mathrm{vs} . \mathrm{N}$ group; ${ }^{\mathrm{b}} \mathrm{P}<0.01 \mathrm{vs}$. M group. $\mathrm{N}$, control group; $\mathrm{M}$, model group; YL, low-dose YHHJ group; YH, high-dose YHHJ group; TBA, total bile acid; TBil, total bilirubin; ALT, alanine transaminase; AST, aspartate aminotransferase.

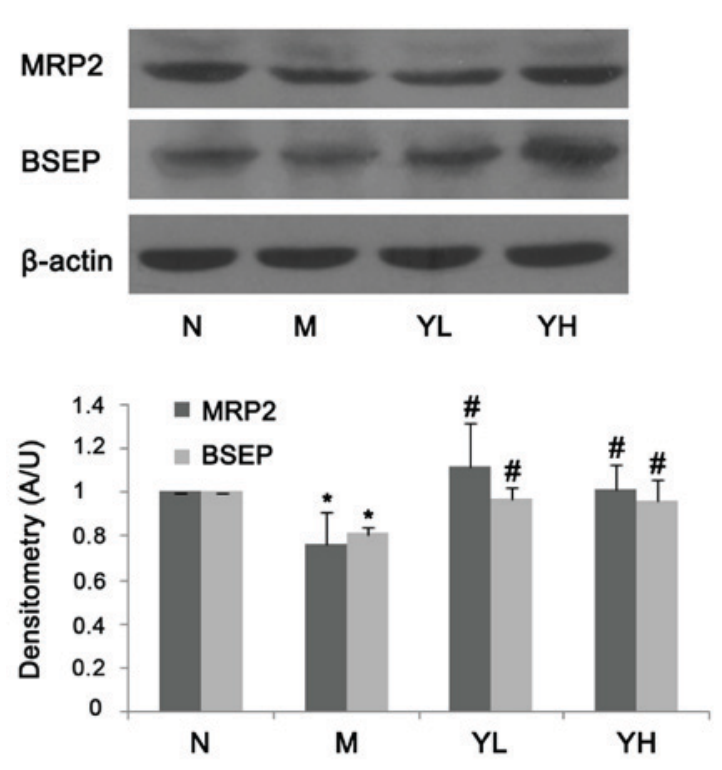

Figure 1. Immunodetection of MRP2 and BSEP in rat livers. MRP2 and BSEP protein expression levels were detected in mixed plasma membranes. The expression of MRP2 and BSEP in each group were presented relative to the expression of the normal group. Data are expressed as the mean \pm standard deviation ( $\mathrm{n}=3$ ), $\beta$-actin was used as a control. ${ }^{*} \mathrm{P}<0.01$ vs. $\mathrm{N}$ group; ${ }^{\prime \prime} \mathrm{P}<0.01$ vs. M group. MRP2, multidrug resistance-associated protein 2; BSEP, bile salt export pump; N, control group; M, model group; YL, low-dose YHHJ group; YH, high-dose YHHJ group.

Effect of YHHJ on the MRNA expression levels of MRP2 and BSEP in EE-induced cholestatic rats. To assess the effect of YHHJ on ICP on a molecular level, mRNA expression levels of MRP2 and BSEP were determined using RT-qPCR. As indicated in Fig. 2, mRNA expression levels of MRP2 (Fig. 2A) and BSEP (Fig. 2B) were significantly downregulated in EE-induced cholestatic rats compared with the $\mathrm{N}$ group $(\mathrm{P}<0.01)$. YL and $\mathrm{YH}$ groups indicated that YHHJ administration significantly increased MRP2 and BSEP mRNA expression levels compared with the $M$ group ( $\mathrm{P}<0.01$; Fig. 2). However, the difference in MRP2 and BSEP mRNA expression levels between the YL and YH groups were not statistically significant.

Cytotoxic effects of YHHJ water extract on cell viability. The cytotoxic effect of YHHJ water extract towards rat hepatocytes was evaluated using the XTT assay. Results indicated that YHHJ displayed cytotoxic effects only at high concentrations
A
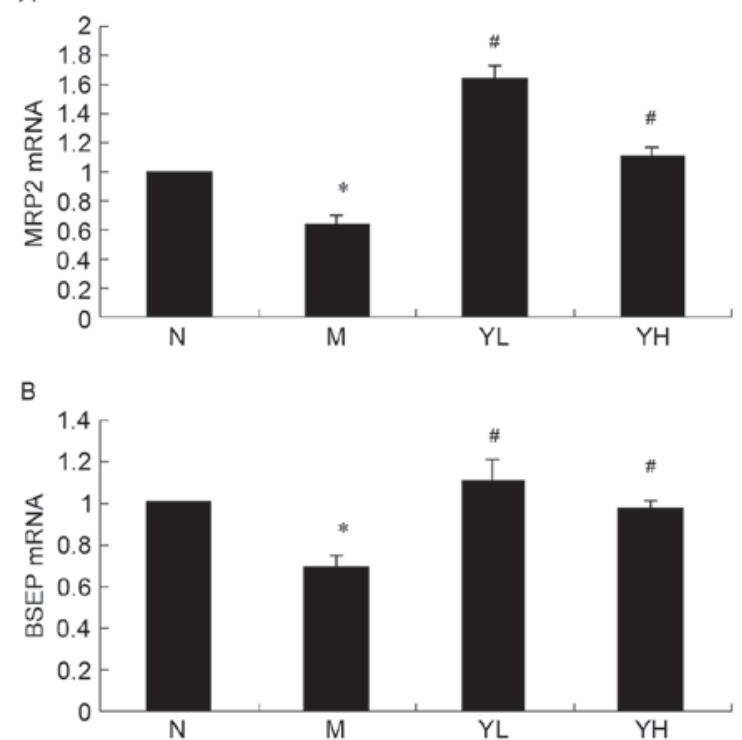

Figure 2. MRP2 and BSEP mRNA expression levels in rat livers. Expression levels of (A) MRP2 and (B) BSEP mRNA were normalized to GAPDH. The mRNA level of MRP2 and BSEP in each group were presented relative to expression of the normal group. Data are expressed as the mean \pm standard deviation $(n=3) .{ }^{*} \mathrm{P}<0.01$ vs. $\mathrm{N}$ group; ${ }^{\#} \mathrm{P}<0.01$ vs. $\mathrm{M}$ group. $\mathrm{MRP} 2$, multidrug resistance-associated protein 2; BSEP, bile salt export pump; $\mathrm{N}$, control group; M, model group; YL, low-dose YHHJ group; YH, high-dose YHHJ group.

(data not shown). The survival rate of the cells was $58.7 \%$ at a concentration of $700 \mu \mathrm{g} / \mathrm{ml} \mathrm{YHHJ}$ water extract and decreased to $41.0 \%$ when treated with $1,000 \mu \mathrm{g} / \mathrm{ml}$. YHHJ demonstrated $\mathrm{CC}_{50}$ at a concentration of $847.5 \mu \mathrm{g} / \mathrm{ml}$ (Fig. 3). YHHJ water extract, however, was indicated to be less toxic toward rat hepatocytes at concentrations of $\leq 300 \mu \mathrm{g} / \mathrm{ml}$, with the survival rate of $\sim 80 \%$. Therefore, only concentrations of $300 \mu \mathrm{g} / \mathrm{ml}$ were selected for the subsequent experiments.

Effect of YHHJ water extract on the protein expression levels of MRP2 and BSEP in EE-induced cholestatic hepatocytes. To assess whether YHHJ water extract affected the protein expression levels in EE-induced cholestatic rat hepatocytes, western blot analysis was performed. Consistent with the changes observed in mRNA expression levels in vivo, EE significantly decreased the protein levels of MRP2 and BSEP (Fig. 4) in the M group at $12 \mathrm{~h}$ post-administration compared with the $\mathrm{N}$ group $(\mathrm{P}<0.01)$. Furthermore, YHHJ water extract 


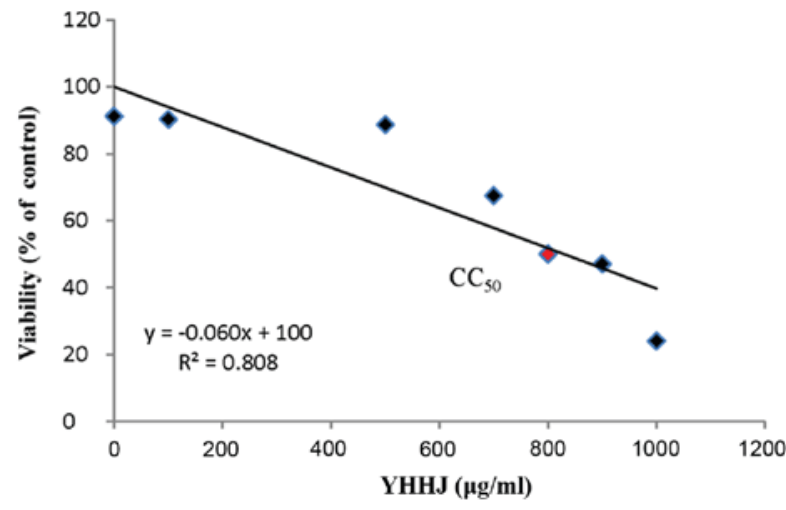

Figure 3. In vitro cytotoxic effect of the YHHJ water extract was determined via XTT assay. The $50 \%$ cytotoxic concentration was the concentration that indicated 50\% toxic effect on rat hepatocytes.
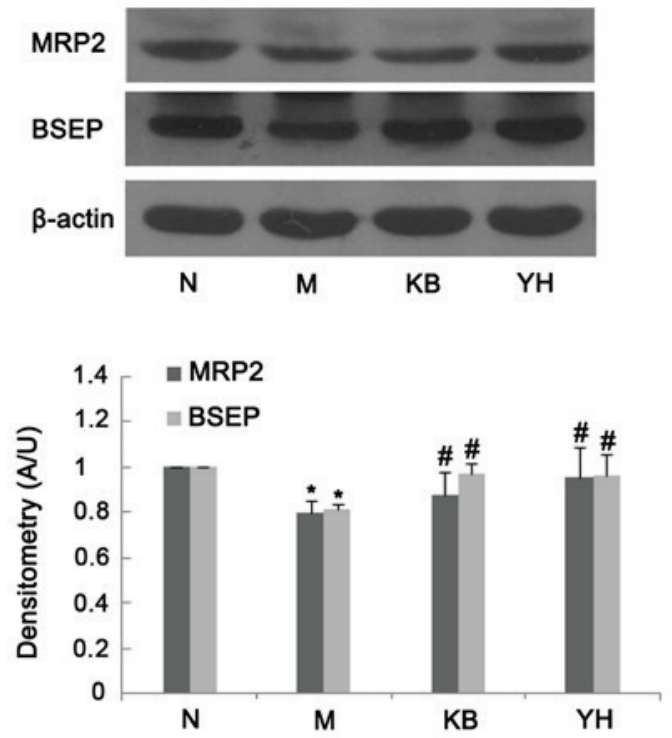

Figure 4. Effect of YHHJ water extract on the protein expression levels of MRP2 and BSEP. Isolated rat hepatocytes were incubated with or without 17- $\alpha$ ethinylestradiol for $12 \mathrm{~h}$; the culture medium was removed and the hepatocytes were treated with YHHJ water extract or drug-free medium for $24 \mathrm{~h}$. The protein expression levels of MRP2 and BSEP were determined by western blot analysis. $\beta$-actin was used as a control. The expression of MRP2 and BSEP in each group were presented relative to expression of the normal group. Data are expressed as the mean \pm standard deviation $(n=3)$. ${ }^{*} \mathrm{P}<0.01$ vs. $\mathrm{N}$ group; ${ }^{\#} \mathrm{P}<0.01$ vs. KB group. MRP2, multidrug resistance-associated protein 2; BSEP, bile salt export pump; $\mathrm{N}$, control group; $\mathrm{M}$, model group; $\mathrm{KB}$, drug-free group; YH, YHHJ water extract group.

significantly increased MRP2 and BSEP (Fig. 4) protein expression levels in EE-induced cholestasis hepatocytes compared with the KB group $(\mathrm{P}<0.01)$.

Effect of YHHJ water extract on the mRNA expression levels of MRP2 and BSEP in EE-induced cholestatic hepatocytes. To assess the effect of the YHHJ water extract on mRNA expression levels of MRP2 and BSEP in EE-induced cholestatic hepatocytes, an in vitro experiment in rat hepatocytes was performed. In agreement with the in vivo studies, the mRNA expression levels of MRP2 (Fig. 5A) and BSEP (Fig. 5B) were significantly downregulated by $\mathrm{EE}$ treatment compared with the $\mathrm{N}$ group $(\mathrm{P}<0.01)$. Compared with the KB group, the
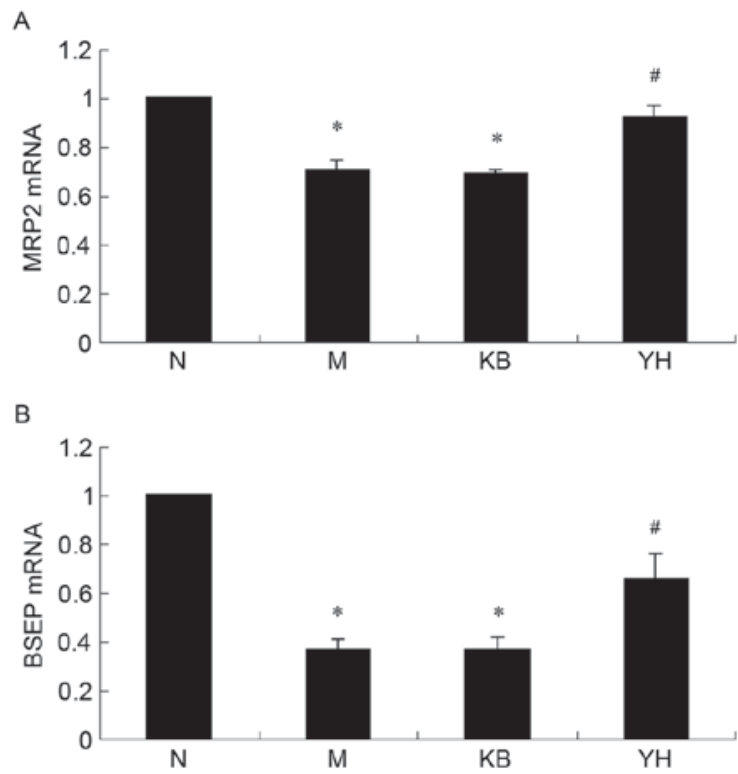

Figure 5. MRP2 and BSEP mRNA expression levels in primary cultured hepatocytes. Isolated rat hepatocytes were incubated with or without $17-\alpha$ ethinylestradiol for $12 \mathrm{~h}$; the culture medium was removed and the hepatocytes were treated with YHHJ water extract or drug-free medium for 24 h. (A) MRP2 and (B) BSEP mRNA expression levels were normalized to GAPDH. Data are expressed as the mean \pm standard deviation $(n=3) .{ }^{*} P<0.01$ vs. $\mathrm{N}$ group; ${ }^{~} \mathrm{P}<0.01$ vs. KB group. MRP2, multidrug resistance-associated protein 2; BSEP, bile salt export pump; N, control group; M, model group; $\mathrm{KB}$, drug-free group; YH, YHHJ water extract group. The mRNA level of MRP2 and BSEP in each group were presented relative to expression in the normal group.

YHHJ water extract significantly reversed the EE-induced downregulation of MRP2 and BSEP ( $<<0.01$; Fig. 5).

\section{Discussion}

ICP typically occurs during the last trimester, when estrogen and progesterone reach their maximum levels (1). Previous studies have reported that reproductive hormones have a role in the etiology of ICP $(21,22)$. EE has been demonstrated to reduce bile flow formation in experimental animals, thus representing a useful model to study estrogen cholestasis (11).

All hormones are metabolized by the liver and an excess of metabolites influences the activity of biliary canalicular transporters (23). Studies have indicated that decreased expression and function of canalicular MRP2 and BSEP are major factors of deteriorated bile flow formation in EE-induced cholestasis $(24,25)$. As reported in the present study, the canalicular transport proteins MRP2 and BSEP are downregulated in EE-induced hepatic rats and primary isolated rat hepatocytes.

YHHJ is derived from Yin Chen Hao Tang, which is one of the most frequently used prescriptions in traditional Chinese medicine practice and has been recognized as a hepatoprotective agent for various types of liver diseases, including cholestasis $(26,27)$.

The present results revealed that YHHJ water extract significantly decreased the levels of serum TBA and TBil in EE-induced cholestasis in rats. However, no significant increase in serum ALT and AST levels were detected in the M group. Similarly, no significant changes were detected in 
ALT and AST levels when YHHJ was administered following EE injection. These differences in liver function tests between the animal model used in the present study and patients with ICP may be due to the estrogen metabolites themselves and the time of the disease formation (28).

In order to study the potential molecular mechanism of YHHJ in the treatment of ICP, the effect of YHHJ on the expression of hepatobiliary transporters MRP2 and BSEP in EE-induced cholestasis in rats and in primary cultured rat hepatocytes was assessed. The present results demonstrated that YHHJ administration significantly increased the protein expression levels of MRP2 and BSEP in EE-induced cholestasis.

To investigate the gene expression of MRP2 and BSEP and validate the upregulation of MRP2 and BSEP proteins, MRP2 and BSEP mRNA expression levels were determined. The data indicated that YHHJ water extract significantly increased MRP2 and BSEP mRNA expression levels at $24 \mathrm{~h}$ after YHHJ water extract treatment.

The present findings determined that, using EE-induced cholestasis in rats and in primary cultured rat hepatocytes, water extract of YHHJ may be a potential therapeutic agent for the treatment of ICP, as indicated in vitro and in vivo. One of the molecular mechanisms associated with the anti-cholestasis effects of YHHJ may involve upregulation of bile acids transporters, MRP2 and BSEP. However, the possible signaling pathways have not been determined.

Based on a recent study, the phosphoinositide 3-kinase/ protein kinase B signaling pathway is associated with estrogen-induced cholestasis in isolated rat hepatocyte couplets and may be responsible for the abnormal function and localization of MRP2 and BSEP (29). In future studies, the effect of YHHJ on the phosphoinositide 3-kinase/protein kinase B signaling pathway will be investigated.

In conclusion, the present study may enhance the understanding of the fundamental aspects of the role of YHHJ in hepatoprotection on EE-induced cholestasis and provides potential insights that may impact medical practice.

\section{Acknowledgements}

The present study was supported by a grant from the National Natural Science Foundation of China (grant no. 81102611).

\section{References}

1. Geenes $\mathrm{V}$ and Williamson C: Intrahepatic cholestasis of pregnancy. World J Gastroenterol 15: 2049-2066, 2009.

2. Lammert F, Marschall HU, Glantz A and Matern S: Intrahepatic cholestasis of pregnancy: Molecular pathogenesis, diagnosis and management. J Hepatol 33: 1012-1021, 2000.

3. Williamson C and Geenes V: Intrahepatic cholestasis of pregnancy. Obstet Gynecol 124: 120-133, 2014.

4. Germain AM, Carvajal JA, Glasinovic JC, Kato CS and Williamson C: Intrahepatic cholestasis of pregnancy: An intriguing pregnancy-specific disorder. J Soc Gynecol Investig 9: 10-14, 2002.

5. Palmer DG and Eads J: Intrahepatic cholestasis of pregnancy: A critical review. J Perinat Neonatal Nurs 14: 39-51, 2000.

6. Williamson C, Hems LM, Goulis DG, Walker I, Chambers J, Donaldson O, Swiet M and Johnston DG: Clinical outcome in a series of cases of obstetric cholestasis identified via a patient support group. BJOG 111: 676-681, 2004.

7. Marrone J, Soria LR, Danielli M, Lehmann GL, Larocca MC and Marinelli RA: Hepatic gene transfer of human aquaporin-1 improves bile salt secretory failure in rats with estrogen-induced cholestasis. Hepatology 64: 535-548, 2016.
8. Lee JM, Trauner M, Soroka CJ, Stieger B, Meier PJ and Boyer JL: Expression of the bile salt export pump is maintained after chronic cholestasis in the rat. Gastroenterology 118: 163-172, 2000.

9. Kullark-Ublick GA and Meier PJ: Mechanism of cholestasis. Clin Liver Dis 4: 357-385, 2000.

10. Fickert P, Zollner G, Fuchsbichler A, Stumptner C, Pojer C, Zenz R, Lammert F, Stieger B, Meier PJ, Zatloukal K, et al: Effects of ursodeoxycholic and cholic acid feeding on hepatocellular transporter expression in mouse liver. Gastroenterology 121: 170-183, 2001.

11. Lee J and Boyer JL: Molecular alterations in hepatocyte transport mechanisms in acquired cholestatic liver disorders. Semin Liver Dis 20: 373-384, 2000.

12. Sheng $G$ and Jun-Ling C: Research progress of traditional Chinese medicine in the treatment of intrahepatic cholestasis of pregnancy. Gansu Zhongyi 16: 6-8, 2003 (In Chinese).

13. Xue-Jun SG: To study thone effect of intrahepatic cholestasis of pregnancy by chinese medicine. Zhonghua Zhongyi Yaoxuekan 32: 1404-1406, 2014 (In Chinese).

14. Cui-Ying Z, Jing-Qin C, Hua C, et al: Clinical research of the effect of YHHJ on the treatment of intrahepatic cholestasis of pregnancy. Jiangsu Zhongyi 1: 8-9, 2000 (In Chinese).

15. Yue Z: Efficacy comparative study of Yin huang mixture (YHHJ) and ursodeoxycholic acid on gestational intrahepatic cholestasis. Heilongjiang Med J 25: 840-842, 2012.

16. Fouassier L, Kinnman N, Lefèvre G, Lasnier E, Rey C, Poupon R, Elferink RP and Housset C: Contribution of mrp2 in alterations of canalicular bile formation by the endothelin antagonist bosentan. J Hepatol 37: 184-191, 2002.

17. Stieger B: The role of the sodium-taurocholatecotransporting polypeptide (NTCP) and of the bile salt export pump (BSEP) in physiology and pathophysiology of bile formation. Handb Exp Pharmacol 201: 205-259, 2011.

18. Garcia F, Kierbel A, Larocca MC, Gradilone SA, Splinter P, LaRusso NF and Marinelli RA: The water channel aquaporin- 8 is mainly intracellular in rat hepatocytes, and its plasma membrane insertion is stimulated by cyclic AMP. J Biol Chem 276: 1247-1252, 2001.

19. Lowry OH, Rosebrough NJ, Farr AL and Randall RJ: Protein measurement with the Folin phenol reagent. J Biol Chem 193: 265-275, 1951.

20. Schmittgen TD and Livak KJ: Analyzing real-time PCR data by the comparative C(T) method. Nat Protoc 3: 1101-1108, 2008.

21. Stapelbroek JM, van Erpecum KJ, Klomp LW and Houwen RH: Liver disease associated with canalicular transport defects: Current and future therapies. J Hepatol 52: 258-271, 2010.

22. Shehta A and EI-Agamy DS: Eeffects of curcumin, resveratrol and ursodeoxycholic acid on ethinylestrdiol and chlorpromazine induced intrahepatic cholestasis in rats. Pharmacologyonline 3: 91-100, 2009.

23. Barth A, Klinger $\mathrm{G}$ and Rost M: Influence of ethinyloestradiol propanolsulphonate on serum bile acids in healthy volunteers. Exp Toxicol Patho 154: 381-386, 2003.

24. Crocenzi FA, SánchezPozzi EJ,Pellegrino JM, Favre CO, Rodríguez Garay EA, Mottino AD, Coleman R and Roma MG: Beneficial effects of silymarin on estrogen-induced cholestasis in the rat: A study in vivo and in isolated hepatocyte couplets. Hepatology 34 : 329-339, 2001.

25. Stieger B, Fattinger K, Madon J, Kullak-Ublick GA and Meier PJ: Drug- and estrogen-induced cholestasis through inhibition of the hepatocellular bile salt export pump (Bsep) of rat liver. Gastroenterology 118: 422-430, 2000.

26. Cheng HY, Lin LT, Huang HH, Yang CM and Lin CC: Yin Chen Hao Tang, a Chinese prescription, inhibits both herpes simplex virus type-1 and type-2 infections in vitro. Antiviral Res 77: 14-19, 2008.

27. Lee TY, Chang HH, Kuo JJ and Shen JJ: Changes of hepatic proteome in bile duct ligated rats with hepatic fibrosis following treatment with Yin-Chen-Hao-Tang. Int J Mol Med 23: 477-484, 2009.

28. Poupon R: Intrahepatic cholestasis of pregnancy: From bedside to bench to bebside. Liver Int 25: 467-468, 2005.

29. Boaglio AC, Zucchetti AE, Sánchez Pozzi EJ, Pellegrino JM, Ochoa JE, Mottino AD, Vore M, Crocenzi FA and Roma MG: Phosphoinositide 3-kinase/protein kinase B signaling pathway is involved in estradiol 17 $\beta$-D-glucuronide-induced cholestasis: Complementarity with classical protein kinase C. Hepatology 52: 1465-1476, 2010.

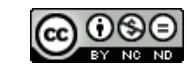

This work is licensed under a Creative Commons Attribution-NonCommercial-NoDerivatives 4.0 International (CC BY-NC-ND 4.0) License. 